\title{
Growing Importance of Cereals in Nutrition and Healthy Life
}

\author{
Mahendra Pal ${ }^{1, *}$, Judit Molnár ${ }^{2}$ \\ ${ }^{1}$ Narayan Consultancy on Veterinary Public Health and Microbiology, Anand Gujarat, India. \\ 21 1/9 Palánkutca, 9200 Mosonmagyaróvár, Hungary.
}

How to cite this paper: Mahendra $\mathrm{Pal}$ Judit Molnár. (2021) Growing Importance of Cereals in Nutrition and Healthy Life. International Journal of Food Science and Agriculture, 5(2), 275-277.

DOI: 10.26855/ijfsa.2021.06.010

Received: March 18, 2021

Accepted: April 16, 2021

Published: April 30, 2021

*Corresponding author: Mahendra Pal, Narayan Consultancy on Veterinary Public Health and Microbiology, Anand Gujarat, India.

Email: palmahendra2@gmail.com

\begin{abstract}
Cereals are key elements of a nutrition and healthy diet and also play a significant role in health promotion due to the useful nutrient content (for example: carbohydrates, vitamins, proteins, minerals). The most important cereals are wheat, barley, rye, and oats, but also known the durum wheat, spelt, buckwheat and as well. The flours, bread, and other baked products produced by cereals also play an important role in disease prevention and international gastronomy. They help to lower cholesterol levels, treat complex metabolic syndrome or obesity, type II diabetes and gastrointestinal diseases with their high vitamin and fibre contents. Cereals are rich sources of B vitamins, which also have a good effect on the balanced functioning of the nervous system. Cereals are also the basis of a healthy nutrition pyramid because of their useful and beneficial properties. Therefore, the first part of the manuscript is the presentation of these cereals and the evaluation of their most important properties and content values. In addition, the publication examines their effect on physiological function. We hope that by presenting the best known cereals, thinkers and scientists can get closer to healthy eating and the opportunities offered by gastronomy through cereals.
\end{abstract}

\section{Keywords}

Baked Products, Cereals, Healthydiet, International Gastronomy

\section{Introduction}

Products made exclusively from cereals are among the products of medium biological value. Therefore, the preservation of the original nutrients of cereals is also great importance during food processing and kitchen technology. Cereals retain $20 \%-80 \%$ of their original vitamin and mineral content during mill processing. Furthermore, $90 \%$ of their fibre contents go into the bran. The use of kitchen technology operations can further increase nutrient depletion. Therefore, in addition to traditional technologies, new processes (for example: hydrothermal) are more often used today. These processes can be used to produce cereal foods with a higher nutritional value, vitamin and mineral contents. In addition, more biologically valuable, darker coloured, fibre rich and mineral rich flours or products made from them are also provided to the consumers. More and more people are interested in these products [1].

Furthermore, cereals are the basis of the healthy diet because of their high quality carbohydrate content [2]. This is evidenced by a number of international recommendations. One of the best known of these recommendations is the healthy eating pyramid, which based on high quality cereals and baked products [3]. In addition, the cereals contain many useful components (fibre, antioxidants, Vitamin B, proteins). The most prominent of these are wheat, barley, rye, and oats. These excellent components can be used to make high-quality bread and baked products through long and slow fermentation. Quality cereals also have beneficial effect on obesity, high cholesterol and II type diabetes mellitus as well [4]. In addition, cereals like durum wheat also have a beneficial effect on the digestive tract [5]. These beneficial effects are due to the high fibre content and the favourable glycaemic index [6]. Positive effects occur when the product is consumed as a part of the healthy diet. This quality and quantity is also specified in nutritional recommendations. The 
daily carbohydrate requirement for a healthy diet is 260-310 g (55-58 Energy\%) in there commendations. During main meals (breakfast, lunch, dinner) the body needs to consume $80 \mathrm{~g}$ of cereals or baked products. Beneficial life style and nutrition can increase disease prevention. It also contributes to the development of international gastronomy. The present communication is an attempt to delineate the growing importance of cereals in nutrition, and healthy life.

\section{The role of cereals in healthy eating}

Barley: Barley is also used in ancient Egypt and the Roman Empire. Barley shows good yield in cool areas. It is rich in fibre and low in gluten. Furthermore, the barley contains vitamin B, minerals and proteins as well [7].

Wheat: The healthy version of wheat is the whole grain. It also contains bran and germ, fibre, polyphenols, vitamins and minerals. The fermentation of bread increases the utilization of the components in the human body [8].

Rye: Rye bread is denser than wheat bread. Rye flour contains the most fibre and phytonutrients. The use of rye flour is the most recommended in the diet of II type diabetes mellitus and obesity [9].

Oats: Oats contain water soluble fibre as beta-glucan. It plays a role in treating high cholesterol or maintaining normal glucose level and intestinal flora as well [10].

The most important nutritional biological values of cereals are summarized in Table 1 . The Table 1 shows the energy, protein, fat and carbohydrate content of $80 \mathrm{~g}$ of wheat, barley, rye, and oats.

Table 1. Energy, protein, fat and carbohydrate contents of wheat (1), barley (2), rye (3) and oats (4.)/80 g

\begin{tabular}{cccccc}
\hline S.N. & Cereals & Energy (kcal) & Protein $(\mathrm{g})$ & Fat $(\mathrm{g})$ & Carbohydrate $(\mathrm{g})$ \\
\hline 1 & Wheat & 277.6 & 11.52 & 1.44 & 52.96 \\
2 & Barley & 290.4 & 8.48 & 1.68 & 58.48 \\
3 & Rye & 264 & 7.68 & 1.36 & 53.6 \\
4 & Oats & 318.4 & 12 & 5.92 & 52 \\
\hline
\end{tabular}

Source: Rodler [11].

\section{Guide to additional cereals}

In addition to the best known cereals, many cereals are used in the international gastronomy as well. These include durum wheat, spelt, buckwheat [12]. These are less known.

Durum wheat flour is often supplemented with wheat flour. Therefore, the baked products have a better texture. The spelt is easier to digest than wheat. It contains a lot of fibre and vitamin $\mathrm{K}$ and it helps with calcium absorption as well. Furthermore, it also contains iron, zinc, and calcium. Buckwheat is a rich source of fibre as a good prebiotic. It has an important role in preventing obesity and maintaining the health of the human gut flora [13].

\section{Conclusions}

Cereals contribute to a balanced and valuable diet due to their useful content values. Cereals are also the basis of the nutrition pyramid, providing excellent fibre sources to help treat many diseases. These include high cholesterol or type II diabetes or normal nervous system function. The major part of the daily carbohydrate intake is provided by cereals to the human body. The most significant grains are wheat, barley, rye and oats. In our manuscript, we pay considerable attention to presenting the beneficial components and health-enhancing effects of cereals. In addition, as with all foods, compliance with hygiene rules and the inhibition of the growth of microorganisms, especially molds, are significant in cereals.

\section{Acknowledgement}

The authors are very thankful to Prof. Dr. R. K. Narayan for going through the manuscript.

\section{Authors' contribution}

All the authors contributed equally. They read the final version, and approved it for the publication.

\section{References}

[1] Léder, F. (2003). New product development opportunities for traditional cereals. Journal of Food Investigation, 49: $238-243$.

[2] Pol, K., Graaf de K., Diepeveen-de Bruin M., Balvers, M., Mars, M. (2020). The effect of replacing sucrose with L-arabinose in drinks and cereal foods on blood glucose and plasma insulin responses in healthy adults. Journal of Functional Foods, 73: 
$1-9$.

[3] Saura, J. R., Reyes-Menendez, A., Thomas, S. B. (2020). Gaining a deeper understanding of nutrition using social networks and user-generated content. Internet Interventions, 20: 1-9.

[4] Hardy, D. S., Garvin, J. T., Xu. H. (2020). Carbohydrate quality, glycaemic index, glycaemic load and cardio metabolic risks in the US, Europe and Asia: A dose-response meta-analysis. Nutrition, Metabolism \& Cardiovascular Diseases, 30: 853-871.

[5] Esfandi, R., Walters, M. E., Tsopmo, A. (2019). Antioxidant properties and potential mechanisms of hydrolyzed proteins and peptides from cereals. Heliyon, 5: 1-26.

[6] Ballester-Sánchez, J., Fernández-Espinar, M. T., Haros, C. M. (2020). Isolation of red quinoa fibre by wet and dry milling and application as a potential functional bakery ingredient. Food Hydrocolloids, 101: 1-9.

[7] Alqudah, A. M., Sallam, A., Baenziger, P. S., Börner, A. (2020). GWAS: Fast-forwarding gene identification and characterization in temperate cereals: lessons from Barley-A review. Journal of Advanced Research, 22: 119-135.

[8] Oliveira, L. C., Alencar, N. M. M., Steel, C. J. (2018). Improvement of sensorial and technological characteristics of extruded breakfast cereals enriched with whole grain wheat flour and jabuticaba (Myrciaria cauliflora) peel. LWT-Food Science and Technology, 90: 207-214.

[9] Jonsson, K., Andersson, R., Knudsen, K. E. B., Hallmans, G., Hanhineva, K., Katina, K., Kolehmainen, M., Kyro, C., Langton, M., Nordlund, E., Laerke, H. N., Olsen, A., Poutanen, K., Tjonneland, A., Landberg, R. (2018). Rye and health-Where do we stand and where do we go? Trends in Food Science \& Technology, 79: 78-87.

[10] Hakala, K., Jauhiainen, L., Rajala, A. A., Jalli, M., Kujala, M., Laine, A. (2020). Different responses to weather events may change the cultivation balance of spring barley and oats in the future. Field Crops Research, 259: 1-10.

[11] Rodler, I. (2005). Nutrient table. Medicina könyvkiadó Rt. Budapest./book/1-765.

[12] Huda, N., Lu, S., Jahan, T., Ding, M., Jha, R., Zhang, K., Zhang, W., Georgiev, M. I., Park, S. U., Zhou, M. (2020). Treasure from garden: Bioactive compounds of buckwheat. Food Chemistry, 335: 1-14.

[13] Kimbell, V. (2018). Sourdough school. Csipetkiadó./book/, 33-34. 